\title{
The Role of Root Tissue Membrane Proteins in Replanting Stress in Rehmannia glutinosa
}

\author{
Fajie Feng ${ }^{1}$, Chuyun Yang ${ }^{1}$, Shangyu Zhan ${ }^{1}$, Shuqiang $\mathrm{Chen}^{1}$, Li Gu ${ }^{1,2}$, Bao Zhang ${ }^{1}$, Aiguo Chen ${ }^{1,3}$, Mingjie $\mathrm{Li}^{1,2}$ and \\ Zhongyi Zhang ${ }^{1,2 *}$ \\ ${ }^{1}$ College of Agriculture, Fujian Agriculture and Forestry University, Fuzhou 350002, P. R. China \\ ${ }^{2}$ Key Laboratory of Ministry of Education for Genetics, Breeding and Multiple Utilization of Crops, Fujian Agriculture and \\ Forestry University, Fuzhou 350002, P. R. China \\ ${ }^{3}$ Qingdao Special Crop Research center, Tobacco Research Institute of Chinese Academy of Agricultural Sciences \\ *For correspondence: zyzhang@fafu.edu.cn \\ Received 03 March 2021; Accepted 07 June 2021; Published 10 July 2021
}

\begin{abstract}
The perennial herbaceous plant, Rehmannia glutinosa Libosch, is one of traditional Chinese medicines with a long history of cultivation and medicinal use. However, in production of $R$. glutinosa, replanting disease severely affected its yield and medicinal quality. Replanting disease is the special stress including biotic and abiotic factors. The membrane proteins system plays the important role in process of plants responding to stress factors. In this study, the differentially expressed root tissue membrane proteins between first planted and replanted $R$. glutinosa were identified through the isobaric tag for relative and absolute quantitation (iTRAQ). As a result, the membrane protein extraction kit could highly effectively extract the membrane proteins from $R$. glutinosa root tissue. A total of 698 differential membrane proteins between first planted and replanted $R$. glutinosa were obtained. Functional analysis revealed that the differential membrane proteins were involved in various metabolic pathways, including transport and breakdown, signal transduction, membrane trafficking and environmental response. Two important molecular events that occurred in cellular membrane of replanted $R$. glutinosa including the imbalance of ROS (Reactive Oxygen Species) metabolism and immune response were identified in this study. When replanted $R$. glutinosa plants faced the complex environment factors in rhizosphere, the proteins located in cellular membrane were often first activated to response to stress stimulus, resulted in the upregulated expression of a large number of $L R R-R L K s$ (Leucinerich repeat receptor-like kinases) receptor proteins. Meanwhile, the $\mathrm{Ca}^{2+}$ signal proteins and related receptor proteins transmitted and responded to the replanting stress, which induced severe oxidative stress response in the cell membrane of $R$. glutinosa, membrane peroxidation, intracellular signal disorder, and eventually produce replanting disease. Our findings provided the theoretical and data foundation for elucidating the key mechanisms associated with replanting stress. (C) 2021 Friends Science Publishers
\end{abstract}

Keywords: Rehmannia glutinosa L.; Replanting stress; Membrane proteins; Differential proteins; iTRAQ

\section{Introduction}

Rehmannia glutinosa L. (Scrophulariaceae) is one of the commonly used Chinese herbal medicines including many important medicinal active components, such as catalpol, reotide, motherwort glycosides, rhubarb polysaccharides, amino acids, stigmasterol, and relevant pharmacological compounds (Zhang et al. 2020; Chen et al. 2021). Modern pharmacological studies shown that $R$. glutinosa owned antioxidant, neuroprotective, anti-aging, and other pharmacological effects (Li and Meng 2015; Wang et al. 2015). However, replanting disease seriously limited the production in the cultivation of $R$. glutinosa. Replanted $R$. glutinosa grown slowly and suffered from pests and diseases, the leaf area and chlorophyll content of replanted $R$. glutinosa reduced obviously, resulting in the roots with inability formatted into tuberous roots, which seriously decreased the yield, quality, and active ingredient accumulation (Li et al. 2012a, b; Guo et al. 2013; Yang et al. 2015; Wang et al. 2021). The replanting disease has attracted thus wide attention that required urgent solving in production of $R$. glutinosa.

Numerous studies shown that replanting disease caused by the changes of the soil properties, the allelochemical autotoxins, and the imbalance of the rhizosphere microbials (Zhu et al. 2007; Zhang et al. 2010). In previous study, many allelochemical autotoxins derived from $R$. glutinosa including some phenolic acids and flavonoids (Chi et al. 2013). Furthermore, the rhizosphere microbes around replanted $R$. glutinosa were found to

To cite this paper: Feng F, C Yang, S Zhan, S Chen, L Gu, B Zhang, A Chen, M Li, Z Zhang (2021). The role of root tissue membrane proteins in replanting stress in Rehmannia glutinosa. Intl J Agric Biol 26:337-348 
transform from bacteria to fungi, leading to continuous proliferation of numerous pathogenic microorganisms (Lin et al. 2011). In addition, the imbalance of the rhizosphere microbials has been confirmed to mainly induced by rhizosphere allelochemical autotoxins (Wu et al. 2015; Zhang et al. 2018). Based on transcriptomics approach, previous studies found that many important signaling pathway including immune responses, ROS generation, programmed cell death, lignin synthesis, $\mathrm{Ca}^{2+}$ signal transduction and ethylene synthesis were significantly activated in replanted $R$. glutinosa (Yang et al. 2015; Li et al. 2017). It remained unclear that how these signals were produced under replanting stress and further resulted in the death of replanted plants.

In the process of plants response to environmental factors, the cellular membrane system plays an important role in sensing of environmental changes (Mansour 2012). The plant membrane system was an important subcellular structure that divided different cell units each other, including the plasma membrane, tonoplast, mitochondrial membrane etc. The plant membrane system has been confirmed to play an essential role in responding and sensing external stress factors, such as low temperature, salt, and drought (Osakabe et al. 2013; Janicka-Russak and Kabala 2015). Replanting disease also constitutes a particular type of stress that is associated with allelochemical autotoxins, harmful microorganisms, and their interaction. As the continuous proliferation of rhizosphere microbes and accumulation of allelochemicals, there were many specific receptors in plasma membrane might be used to respond to the stress in replanted $R$. glutinosa. These receptors likely further induced downstream response. In addition to the receptors presented in the plasma membrane, many channels and receptors located in intracellular membrane were found closely relate to stress response and cell death (Huang et al. 2018). Numerous studies have proved that the formation of replant disease was induced by the micro-ecological imbalance in rhizosphere mediated by allelochemical autotoxins (Qiu et al. 2010; Li et al. 2012a, b; Zhao et al. 2016). However, the replant soil in the rhizosphere was only harmful to $R$. glutinosa but has no harmful effect on other crops. This indicated that there was a specific signal transduction system in $R$. glutinosa to sense and respond to the replant stress. Membrane receptor protein is a key factor for plants to respond to environmental stress, replant disease is a complex stress for $R$. glutinosa. Previous studies have found that the root vitality of replanted $R$. glutinosa was very low and the membrane peroxidation was seriously ( $\mathrm{Wu}$ et al. 2015). However, the studies did not involve in membrane proteins that specifically respond to replant stress, and how the plants receive, transmit and respond to the signals was also unknown. The reception of signals is the prerequisite of signal transduction; receptor proteins located in the membrane were the main channels for plants to perceive signals from the external environment. Therefore, study on the membrane receptor proteins in replanted $R$. glutinosa has the great significance to clarify the death behaviorinducing by replanted practice.

The successful extraction of membrane proteins was important basis for the functional study of differential membrane proteins. The membrane protein extraction methods in animals are relatively established, while the opposite is true for plants. Two main ways of membrane proteins extraction currently exist: one is the two-phase partition method, and another is the membrane protein extraction kit (Pang et al. 2010; Pan et al. 2013). In this study, the extraction efficiency of two ways were compared to obtain a suitable method for the membrane proteins extraction of tuberous roots. Based on above optimized methods, membrane proteins were extracted from the tuberous roots of $R$. glutinosa. Simultaneously, to screen critical membrane receptor proteins in response to replanting stress, the abundance level and kinds of membrane proteins in $R$. glutinosa samples identified through iTRAQ technologies. The expression pattern of receptor proteins which under the factors of microbes and allelochemical autotoxins that closely related to replanting disease formation were investigated by qRT-PCR methods. This study provided a theoretical basis for revealing the molecular mechanisms of replanting stress in $R$. glutinosa.

\section{Materials and Methods}

\section{Experimental materials}

In this study, the $R$. glutinosa (cultivar "Wen 85-5", which was widely planted and had high medicinal value, and replanting disease severely affected its yield and medicinal quality) was cultivated in the experimental field which located in Jiaozuo City, Henan province, China $\left(34^{\circ} 48^{\prime} \mathrm{N}\right.$ to $35^{\circ} 30^{\prime} \mathrm{N}, 112^{\circ} 02^{\prime} \mathrm{E}$ to $113^{\circ} 38^{\prime} \mathrm{E}$ ), an $R$. glutinosa production area. The $R$. glutinosa were named as the first planted $R$. glutinosa $(\mathrm{FP})$ which were planted in a section of the experimental field where $R$. glutinosa had not been planted for 10 years. Moreover, $R$. glutinosa were named as the second planted $R$. glutinosa (SP) which were planted in the experimental field where $R$. glutinosa had been planted in the previous year. A previous study showed that the damage of SP $R$. glutinosa was most serious at about 90 days after planting (Yang et al. 2014). During the key period of replanting damage to $R$. glutinosa, we obtained the root samples of FP and SP, three biological replicates respectively, each replicate was 3-7 plants, we collected root tissues (the entire roots of the FP and SP, pooled and mixed respectively). The samples were collected and stored at $-80^{\circ} \mathrm{C}$ in preparation for downstream experiments.

\section{Protein extraction and extraction efficiency analysis of the $R$. glutinosa root samples}

In order to select the appropriate membrane protein 
extraction method of $R$. glutinosa root tissues, the membrane protein kits and two-phase partition method were used to analyze the concentrations and quality of the extracted membrane proteins. Then the most efficient method was used to extract the membrane proteins of FP and SP samples (three biological replicates respectively, each replicate was 3-7 plants).

Method 1: Membrane protein extraction kit A (Minute $^{\mathrm{TM}}$ total membrane and plasma membrane extraction kit SM-005; Invent Biotechnologies, Plymouth, Minnesota, USA) (Zhang et al. 2019; Su et al. 2021; Yuan et al. 2021). Extraction processes: $1-1.5 \mathrm{~g} R$. glutinosa root tissue samples were grinded into powder in liquid nitrogen and placed into $10-15 \mathrm{~mL}$ centrifuge tubes to which $2 \mathrm{~mL}$ of buffer A was added. The tubes were mixed for 2-3 min, centrifuged for $5 \mathrm{~min}$ at $500 \times \mathrm{g}$ and $4^{\circ} \mathrm{C}$, and then transferred the supernatant to a new $2 \mathrm{~mL}$ centrifuge tube. The tube was centrifuged for $10 \mathrm{~min}$ at $10,000 \times \mathrm{g}$ and $4^{\circ} \mathrm{C}$, and transferred the supernatant to a new $2.0 \mathrm{~mL}$ centrifuge tube and centrifuged for $30 \mathrm{~min}$ at $14,000 \times \mathrm{g}$ and $4^{\circ} \mathrm{C}$. After removing the supernatant (cytoplasmic protein), the remaining pellets was resuspended using $0.3 \mathrm{~mL}$ of buffer $\mathrm{B}$ by a pipette gun. The resuspension was then transferred to a new centrifuge column and centrifuged for $10 \mathrm{~min}$ at 14,000 $\times \mathrm{g}$ and $4^{\circ} \mathrm{C}$, transferred the supernatant to a new $2 \mathrm{~mL}$ centrifuge tube to which $1.6 \mathrm{~mL}$ of pre-cooled PBS was added. The tube was inverted several times to mix the solution and then centrifuged for $30 \mathrm{~min}$ at $14,000 \times \mathrm{g}$ and $4{ }^{\circ} \mathrm{C}$. The resulting precipitate (pellet) was membrane proteins.

Method 2: Membrane protein extraction kit B (BB3152-2 plant membrane protein extraction kit; Best Bio Biology) (He et al. 2018; Zhuang et al. 2019; Du et al. 2020). Extraction processes: $2 \mu \mathrm{L}$ of protease inhibitor was placed into each $500 \mu \mathrm{L}$ extract $\mathrm{A}$ as a reference, and the extract premix was prepared, mixed well, and set it on ice. Then, 1-1.5 g of $R$. glutinosa root tissue samples were grinded into powder in liquid nitrogen and added to a pre-cooled 10-15 $\mathrm{mL}$ centrifuge tube to which $2 \mathrm{~mL}$ extract $\mathrm{A}$ was added. The tube was mixed and oscillated at $2-8^{\circ} \mathrm{C}$ for $2-3 \mathrm{~h}$ and then centrifuged for $5 \mathrm{~min}$ at $12,000 \times \mathrm{g}$ and $2-8^{\circ} \mathrm{C}$. Following this, $40 \mu \mathrm{L}$ extract B was added to the supernatant and mixed thoroughly, and then placed in water bath at $37^{\circ} \mathrm{C}$ for $10 \mathrm{~min}$. The solution was then centrifuged for $5 \mathrm{~min}$ at $1,000 \times \mathrm{g}$ and $37^{\circ} \mathrm{C}$. Then the solution had divided into two layers, and the upper layer was removed carefully, leaving about $200 \mu \mathrm{L}$ of liquid at the bottom of the tube. The solution was diluted with 1 to 2 volumes of the membrane protein solution to obtain the membrane protein samples.

Method 3: Two-phase partition method (Santoni 2007). For this method, 1-1.5 g of root samples were grinded into powder in liquid nitrogen and placed into $10-15 \mathrm{~mL}$ precooled centrifuge tubes to which $10 \mathrm{~mL}$ pre-cooled protein extract was added. The solutions were pumping evenly with a pipette, centrifuged for $15 \mathrm{~min}$ at $8,000 \times \mathrm{g}$ and $4^{\circ} \mathrm{C}$, and transferred the supernatant to a new centrifuge tube, centrifuged for $1 \mathrm{~h}$ at $100,000 \times \mathrm{g}$ and $4^{\circ} \mathrm{C}$ (supernatant is the cytoplasmic protein, the pellet is a microsomal fraction). Then, the supernatant was removed and the extraction solution was re-added to the pellet and centrifuged for $1 \mathrm{~h}$ at $100,000 \times \mathrm{g}$ and $4^{\circ} \mathrm{C}$, then, removed the supernatant and the pellet dissolved in a certain amount of extraction solution, and then stored at $-80^{\circ} \mathrm{C}$.

\section{Extraction efficiency analysis of the different membrane protein extraction methods}

The protein integrity was detected by SDS-PAGE (Sodium Dodecyl Sulfate Polyactylamide Gel Electrophoresis). The extraction efficiency of $R$. glutinosa root tissue membrane proteins was quantitatively analyzed by BCA kit (Easy II Protein Quantitative Kit, Trans Gen Biotech). The specific analysis processes were as follows: bovine serum albumin (BSA) standard solution was diluted to $500 \mu \mathrm{g} / \mathrm{mL}$ with PBS (Phosphate Buffer Saline). Based on the number of samples, the BCA (Bicinchoninic acid) Solution A and BCA Solution B were diluted in a 50:1 ratio into the working solution, mixed well, and set aside for $24 \mathrm{~h}$ at $4^{\circ} \mathrm{C}$. Then, eight $1.5 \mathrm{~mL}$ centrifuge tubes were numbered respectively and used for the compound of diluted standard solution. After diluting the sample to be tested 10 times with $1 \times \mathrm{PBS}, 50 \mu \mathrm{L}$ of the solution was added to $500 \mu \mathrm{L}$ of BCA working solution. The tube was mixed by oscillation and then placed at $37^{\circ} \mathrm{C}$ for $30-90 \mathrm{~min} .5 \mu \mathrm{L}$ of the reaction product was then obtained and placed in centrifuge tube $\mathrm{A}$ as a negative control. The absorbance of the sample was measured with a NanoDrop 2000 spectrophotometer (http://thermofisher.biomart.cn) at a wavelength of $562 \mathrm{~nm}$ and a standard curve was constructed to calculate the concentration of the protein samples. Then, $5 \times$ loading buffer was added to $20 \mu \mathrm{g}$ of each diluted protein sample, and then placed in a boiling water bath for $5 \mathrm{~min}$. These were assessed by $12.5 \%$ SDS-PAGE electrophoresis (constant current $14 \mathrm{~mA}, 90 \mathrm{~min}$ ), stained with Coomassie brilliant blue, and the BSA protein quantified by a spectrophotometer.

\section{Classification and identification of the proteins obtained by different membrane protein extraction methods}

Protein samples with higher extraction efficiency were subjected to protein reductive alkylation and enzymolysis. Based on the FASP (Filter Aided Proteome Preparation) method (Wisniewski et al. 2009) for the enzymolysis of protein, the specific processes were as follows: $20 \mu \mathrm{g}$ quantitative protein sample was added to five volumes of pre-cooled acetone and set aside at $-20^{\circ} \mathrm{C}$ for $1 \mathrm{~h}$, after which the protein had fully precipitated. Then, centrifuged for $10 \mathrm{~min}$ at $12,000 \times \mathrm{g}$ and $4^{\circ} \mathrm{C}$ and the precipitate (pellet) were freeze-dried by vacuum concentration. $10 \mu \mathrm{L}$ of the protein re-dissolving solution was used to fully dissolve the protein precipitate, to which $40 \mu \mathrm{L}$ of protein reduction 
solution was added and then reacted at $37^{\circ} \mathrm{C}$ for $1 \mathrm{~h}$. Following this, $40 \mu \mathrm{L}$ of protein alkylation solution (9 $\mathrm{mol} / \mathrm{L}$ urea, $50 \mathrm{mmol} / \mathrm{L}$ IAA, $50 \mathrm{mmol} / \mathrm{L} \mathrm{NH}_{4} \mathrm{HCO}_{3}$ ) was added and the solution was then reacted at room temperature for $10 \mathrm{~min}$. The reduced alkylated protein solution was then added to a $10 \mathrm{kD}$ ultrafiltration tube, centrifuged for $20 \mathrm{~min}$ at $12,000 \times \mathrm{g}$, and then discarded the bottom solution in the collection tube. Ammonium bicarbonate $(150 \mu \mathrm{L} 1 \mathrm{mmol} / \mathrm{L})$ was added and centrifuged for $20 \mathrm{~min}$ at $12,000 \times \mathrm{g}$. Once again, the bottom solution of the collecting tube was discarded, and this process was repeated three times. The resulting solution was placed in a new collection tube to which $100 \mu \mathrm{L}$ sequencing grade tryps in solution $(5 \mathrm{ng} / \mu \mathrm{L})$ was added, and the reaction continued at $37^{\circ} \mathrm{C}$ for $12 \mathrm{~h}$. Following this, the tube was centrifuged for $10 \mathrm{~min}$ at $12,000 \times \mathrm{g}$ and the digested peptides were collected. $50 \mu \mathrm{L}$ of ammonium bicarbonate $(1 \mathrm{mmol} / \mathrm{L})$ was added to the ultrafiltration tube and centrifuged for $10 \mathrm{~min}$ at $12,000 \times \mathrm{g}$. The bottom solution was collected from the tube and combined with the previous solution, and then freeze-dried (lyophilized). To identify the properties of the proteins, the peptide samples obtained after proteolysis were detected by mass spectrometry.

\section{Extraction and purification of the root tissue membrane proteins of FP and SP R. glutinosa}

We used the method 2 (membrane protein extraction kit B) to extract the membrane proteins of $R$. glutinosa root tissue samples, using the resulting samples for the downstream experiments. Specifically, 30-fold volume $(\mathrm{m} / \mathrm{v})$ of SDS (sodium dodecyl sulfate) lysis buffer was added to the resulting membrane protein sample and the pellet was resuspended by vortex mixing and then placed in a boiling water bath for $5 \mathrm{~min}$, sonicated $(80 \mathrm{~W}, 10 \mathrm{~s}$ on, $15 \mathrm{~s}$ off, 10 cycles), and then placed back in the boiling water bath for $15 \mathrm{~min}$. Following centrifuged for $40 \mathrm{~min}$ at $14,000 \times \mathrm{g}$, filtered the supernatant through the $0.22 \mu \mathrm{m}$ membrane and collected the filtrate. The BCA method was used for protein quantification: the samples were aliquot and stored at $-80^{\circ} \mathrm{C}$. Taken $20 \mu \mathrm{g}$ of protein from each sample, to which $5 \times$ loading buffer was added, and the tubes were placed in a boiling water bath for $5 \mathrm{~min}$. The protein was quantified using 12.5\% SDS-PAGE electrophoresis (constant current $14 \mathrm{~mA}, 90 \mathrm{~min}$ ) and Coomassie Brilliant Blue staining. And isobaric tag for relative and absolute quantitation (iTRAQ) analysis was used for the extracted protein samples, and the samples were also chromatographed and analyzed by QExactive mass spectrometry.

\section{Data identification method}

The original mass spectrometry analysis data were in RAW file format, Mascot 2.2 (Matrix Science) and Proteome Discoverer 1.4 software (Thermo Fisher Scientific) were used for library identification and quantitative analysis
(Huang et al. 2013). The Gene Ontology (GO) function annotation of the target protein collection using Blast $2 \mathrm{GO}$, the process can be roughly divided into four steps: Blast, GO entry extraction, GO annotation, and supplementary annotation. In the Kyoto Encyclopedia of Genes and Genomes (KEGG) database, KO (KEGG Orthology) is a classification system of genes and their products. Orthologs and their products with similar functions in the same pathway are grouped together and given the same $\mathrm{KO}$ (or $\mathrm{K}$ ) tag. The Pathway Enrichment Analytics free online database analysis software tool Omic Share (www.omicshare.com/tools) was used for the enrichment analysis.

\section{PCR detection of pathogen infection in R. glutinosa}

Fusarium oxysporum f. spp. is a specific pathogen that our research team isolated from the rhizospheric soil of replanted $R$. glutinosa. Our preliminary experiments have confirmed that the rhizosphere allelochemical autotoxin of SP $R$. glutinosa can significantly promote $F$. oxysporum proliferation (Li et al. 2016). In this study, we used $F$. oxysporum to infect $R$. glutinosa, and obtained root samples when the infected $R$. glutinosa started exhibiting symptoms of infection. The root samples were subjected to electron microscopic analysis and DNA extraction. PCR primers were designed for the pathogenic fungi according to the reported conserved sequences in the fungal ribosomal transcribed spacer region. The primers of $F$. oxysporum are ITS1-F (5'- CTTGGTCATTTAGAGGAAGTAA-3') and ITS4-R (5'-TCCTCCGCTTATTGATATGC-3') were synthesized with reference to $\mathrm{Wu}$ et al. (2015) (Sun Ya Biotechnology Co., Ltd. Fuzhou, China). The PCR reaction mixture was $20 \mu \mathrm{L}$, consisting of $1.6 \mu \mathrm{L}$ of dNTPs (25 $\mu \mathrm{mol} / \mathrm{L}$ ), $2.0 \mu \mathrm{L}$ of $10 \times$ ETaq buffer (containing $\mathrm{Mg}^{2+}$ ), 1 $\mu \mathrm{L}$ of primer $(10 \mu \mathrm{mol} / \mathrm{L}), 0.1 \mu \mathrm{L}$ of ETaq enzyme, $1 \mu \mathrm{L}$ template DNA (10 ng), and $13.3 \mu \mathrm{L} \mathrm{H}_{2} \mathrm{O}$ (Sangon Biotech). The PCR reaction conditions were as follows: predenaturation at $95^{\circ} \mathrm{C}$ for $5 \mathrm{~min}$, followed by 35 cycles of denaturation at $95^{\circ} \mathrm{C}$ for $30 \mathrm{~s}$, annealing at $55^{\circ} \mathrm{C}$ for $45 \mathrm{~s}$, extension at $72^{\circ} \mathrm{C}$ for $1 \mathrm{~min}$, and a final extension at $72^{\circ} \mathrm{C}$ for $3 \mathrm{~min}$. After the reaction, the products were stored at $4^{\circ} \mathrm{C}$ for later use. DL Marker 2000 (Sangon Biotech) was used as a standard molecular marker and the PCR products were detected by $1 \%$ agarose gel electrophoresis. The relative gene expression of the genes was calculated using the $2^{-\triangle \Delta \mathrm{Ct}}$ method (Livak and Schmittgen 2001).

\section{Results}

Validity analysis of the membrane proteins extraction methods

In order to effectively extract membrane proteins from the root tissue of $R$. glutinosa, three methods were used for extraction respectively. As a result, there were obvious differences in the protein concentrations obtained by the three methods, in which, $23 \mu \mathrm{g} / \mathrm{mL}$ of the protein abundance 
extracted by method $1,400 \mu \mathrm{g} / \mathrm{mL}$ of the protein abundance extracted by method 2 , and $580 \mu \mathrm{g} / \mathrm{mL}$ of the protein abundance extracted by method 3 . The protein concentration obtained by method 1 was relatively lower in comparison to other two methods and did not fully meet the requirements for further protein experiments. Thus, method 2 and method 3 were further compared for the efficiency of membrane protein extraction. The candidate membrane proteins obtained by method 2 and method 3 were analyzed by LCMS/MS, and the peptide fragments obtained were aligned with the database of $R$. glutinosa total proteins. There were 870 and 526 proteins were extracted by the method 2 and method 3, respectively, of which, 532 and 289 proteins were respectively clearly annotated as membrane proteins. Therefore, method 2 indicated have better enrichment efficiency of membrane proteins compared to the method 3. Finally, method 2 was used for the differential membrane proteins analyses of the FP and SP $R$. glutinosa.

\section{Membrane protein library construction of the FP and SP R. glutinosa}

To study the differentially expressed membrane proteins between the FP and SP $R$. glutinosa, the membrane proteins of the FP and SP R. glutinosa root tissues (each sample three biological replicates) were extracted by method 2 . The acquired proteins were identified by the iTRAQ technique. By comparing the results of ITRAQ and LC-MS/MS with earlier constructed $R$. glutinosa proteomics database, a total of 4,285 proteins were obtained from the FP and SP, including 1,753 non-annotated and 2,532 annotated proteins in the UniProtKB database. Moreover, 1,465 out of 2,532 were identified as membrane proteins, which contain plasma membrane, chloroplast membrane, mitochondrial membrane, Golgi membrane etc. The extraction rate of membrane proteins reached $57.86 \%$ (Fig. 1c). The highest peptide coverage was $73.13 \%$ and there were 1,700 proteins with a coverage degree over 10 . A total of 1,837 proteins were detected in the samples of SP $R$. glutinosa, of which 633 had $\geq 2$ unique peptides. A total of 2,541 proteins were detected in the FP $R$. glutinosa, of which 1,006 had $\geq 2$ unique peptides. The obtained protein sequences provided the basis for the further identification of differential membrane proteins between the FP and SP R. glutinosa.

\section{Difference analysis of the root membrane proteins between the FP and SP R. glutinosa}

In order to identify the membrane proteins which respond to replanting stress, we screened out 912 differential proteins between the FP and SP samples based on the $P<0.05$ and $>$ 1.2 fold. A total of 214 non-membrane proteins were removed from the 912 differentially expressed proteins through the UniProt online software. The remaining 698 proteins were annotated as membrane proteins, of which, there were 339 membrane proteins were up-regulated, 359 membrane proteins were down-regulated in the SP R. glutinosa (Fig. 1a, b).

To analyze the functions of the differential membrane proteins between the FP and SP $R$. glutinosa, we assessed those proteins using GO and KEGG. Among up-regulated expressed membrane proteins in the SP $R$. glutinosa, a total of 339 differential membrane proteins matched to 5,341 GO entries, 330 GO terms were obtained by GO enrichment analysis. Those proteins mainly involved in trans-membrane transport, vesicle-mediated transport, intracellular transport, protein transport, and ion transport (Fig. 2a, Fig. 3a). Among the 359 down-regulated membrane proteins in the SP $R$. glutinosa, a total of $336 \mathrm{GO}$ terms were obtained by GO enrichment analysis, mainly included response to chemical stimulation, metabolism of small-molecule metabolites, and response to stress (Fig. 2b, Fig. 3b). Cellular location analysis showed that the differential membrane proteins were localized to the cellular membrane (GO: $0016020\left[1.64 \mathrm{e}^{-13}\right]$ ).

KEGG functional analysis was performed on the screened differentially expressed membrane proteins. There were 340 metabolic pathways were significantly enriched, of which, 161 pathways in carbohydrate metabolism (such as starch and sucrose metabolism, glycolytic or gluconeogenesis, pentose phosphate pathway, and ascorbate metabolism), 18 pathways in plant-pathogen interaction, 42 pathways were participated in protein folding, sorting, and degradation processes (endoplasmic reticulum protein synthesis, protein export, RNA degradation etc.), 56 in transcriptional translation processes (such as ribosomes, RNA transport), 47 in protein transport and degradation pathways, including endocytosis, peroxisomes, phagosomes and autophagy, and 24 in signal transduction pathways and membrane trafficking (e.g., plant hormone signaling, phosphoinositide signaling transduction, $\mathrm{ABC}$ transporter). In addition, 30 significantly enriched pathways were associated with metabolite transport pathways, including endoplasmic reticulum protein processing, amino acid biological processes, carbon metabolism, sucrose and starch metabolism, oxidative phosphorylation, and secondary metabolism (terpenoids, polyketides metabolism etc.) (Fig. 4a). The up-regulated expressed membrane proteins in SP $R$. glutinosa were mainly involved in protein synthesis in the endoplasmic reticulum, glycerophospholipid metabolism, oxidative phosphorylation, endocytosis, phagosomes, sucrose and starch metabolism, protein export, quinone biosynthesis, and other secondary metabolism (Fig. 4b). The down-regulated expressed membrane proteins in SP $R$. glutinosa were primarily involved in carbon metabolism, amino acid biosynthesis, glycolysis and gluconeogenesis, peroxisomes, pentose phosphate pathway, and carbon assimilation within photosynthetic tissues (Fig. 4c).

\section{Integration analysis of differentially expressed membrane proteins between FP and SP $R$. glutinosa root samples}

In order to describe the function of differential membrane 
(a)

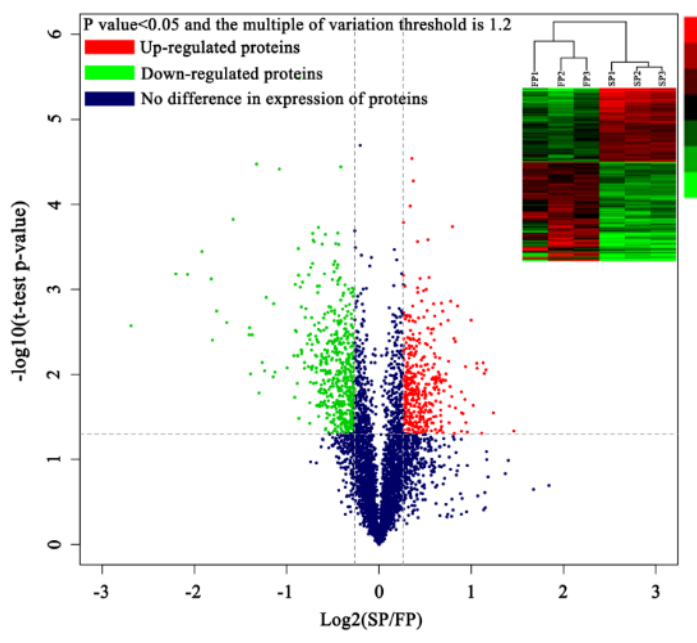

(b) 0.50
0.33
0.17
0.00
-0.17
-0.33
-0.50

(c)
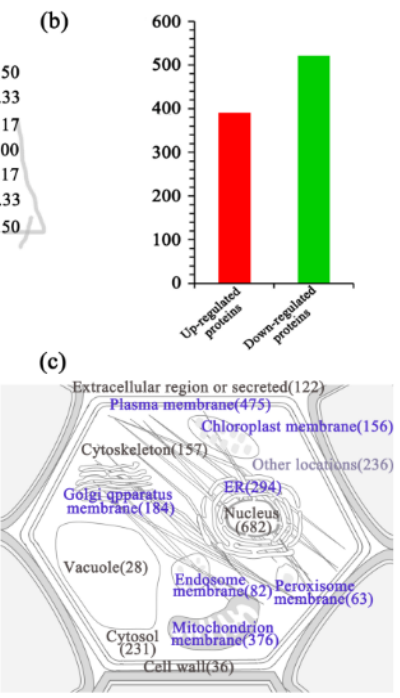

Fig. 1: Differently expressed proteins in root tissue of FP and SP $R$. glutinosa (a) iTRAQ protein differential expression profile: $P$-value < 0.05 , the threshold of variation difference was 1.2 folds, which means that SP/FP values more than 1.2 folds or less than 0.83 were considered differentially expressed, (b) Analysis and statistics of the differentially expressed proteins, (c) Positional distribution of differential proteins in root tissue of SP and FP $R$. glutinosa

$\mathrm{FP}=$ the $R$. glutinosa first planted in the field; $\mathrm{SP}=$ the $R$. glutinosa replanted in the same field continuously
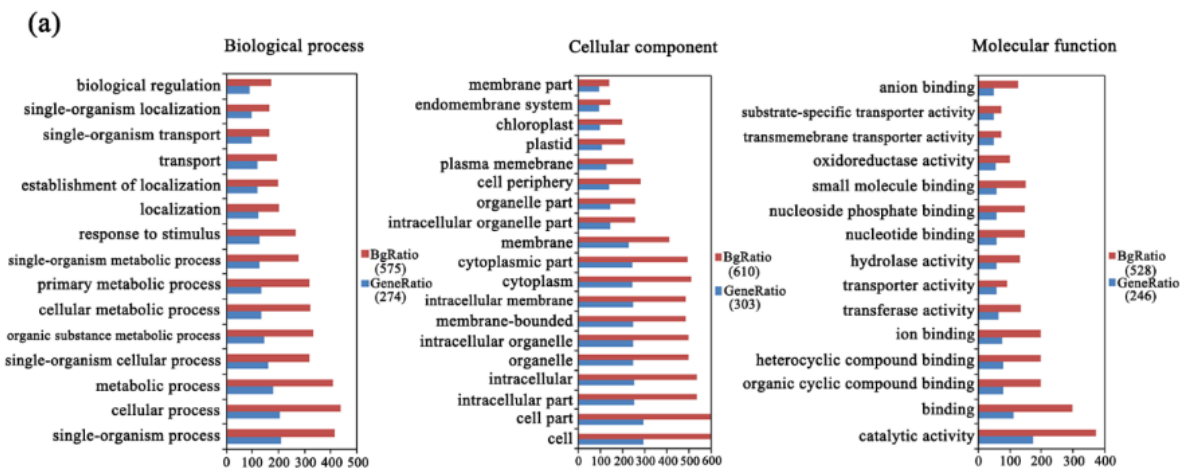

(b)

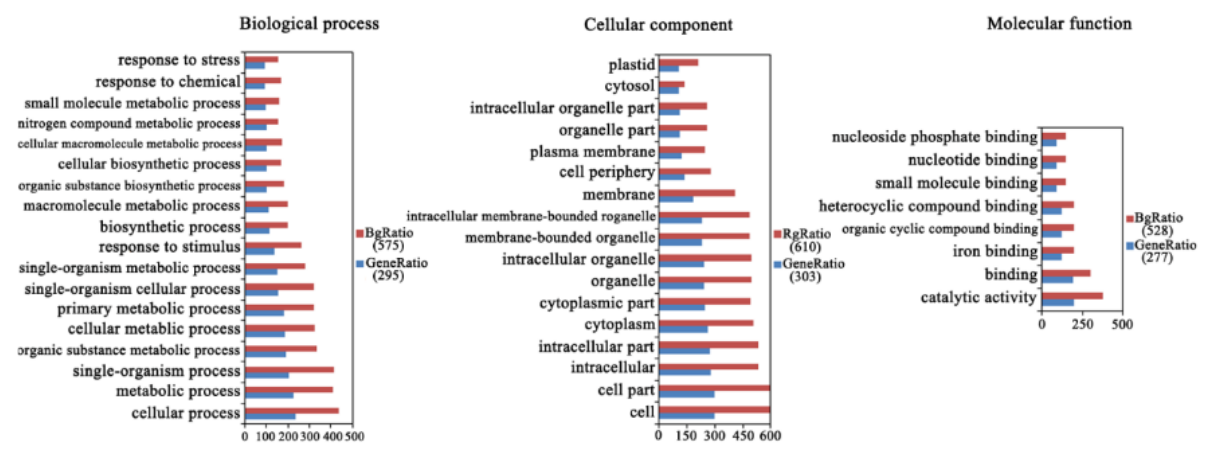

Fig. 2: GO enrichment analysis of the biological process part, cellular component part, and molecular function part about differently expressed membrane proteins (a) significantly up-regulated expressed membrane proteins in replanted $R$. glutinosa, (b) significantly down-regulated expressed membrane proteins in replanted $R$. glutinosa

proteins in more detail, a comprehensive functional classification of those proteins was conducted based on the annotations of the GO, KEGG, and $\mathrm{Nr}$ databases. The results indicated that differential membrane proteins were involved in various metabolic pathways, including transport and breakdown, signal transduction, terpene and polyketide 
Table 1: The main classifications of the differentially expressed membrane proteins between FP and SP R. glutinosa

\begin{tabular}{|c|c|c|c|}
\hline Class & Pathway & Protein Number & Proteins \\
\hline \multirow[t]{3}{*}{ Transport and catabolism } & Endocytosis & 22 & PRAF1、PIP5K、DNM、HSPA4、RAB7A、VPS23、VPS28、VPS4 ... \\
\hline & Peroxisome & 11 & IDH1、ACOX1、CAT、ACAA1、PEX3、PEX7、PMP34... \\
\hline & Phagosome & 11 & ATPeV1D、ATPeV1G、RAC1、RAB... \\
\hline \multirow[t]{2}{*}{ Signal transduction } & Plant hormone signal transduction & 13 & PTI1、AUX1、TIR1、GH3、GID1、SNRK2、BSK、BIN2、CTR1 ... \\
\hline & Phosphatidylinositol signaling system & 6 & PI4KB、PIP5K、DGK、PTEN、CALM \\
\hline Metabolism of terpenoids and polyketides & Terpenoid backbone biosynthesis & 6 & atoB、SDS、chlP、DHDDS、FLDH \\
\hline Membrane transport & $\mathrm{ABC}$ transporters & 5 & $\mathrm{ABCB}$ \\
\hline \multirow[t]{5}{*}{ Lipid metabolism } & Glycerophospho lipid metabolism & 18 & DGK、HM13、plcC、PRAF1、LYPLA2 ... \\
\hline & alpha-Linolenic acid metabolism & 9 & EPT1、EIF3D、ACAA1、OPCL1、HPL... \\
\hline & Glycerolipid metabolism & 8 & ALDH、DGK、 galA、AGPAT9、AGPAT8、LPT1... \\
\hline & Fatty acid degradation & 7 & ALDH $、$ atoB、ACOX $1 、$ ACAA $1 \ldots$ \\
\hline & Steroid biosynthesis & 6 & DHCR7、CAS、CYP51、SMT2、CPI1、CYP710A \\
\hline Environmental adaptation & Plant-pathogen interaction & 18 & CALM、HSP90B、CDPK、PTI1 LRR-RLK、PTI1、CML、RPM1... \\
\hline
\end{tabular}
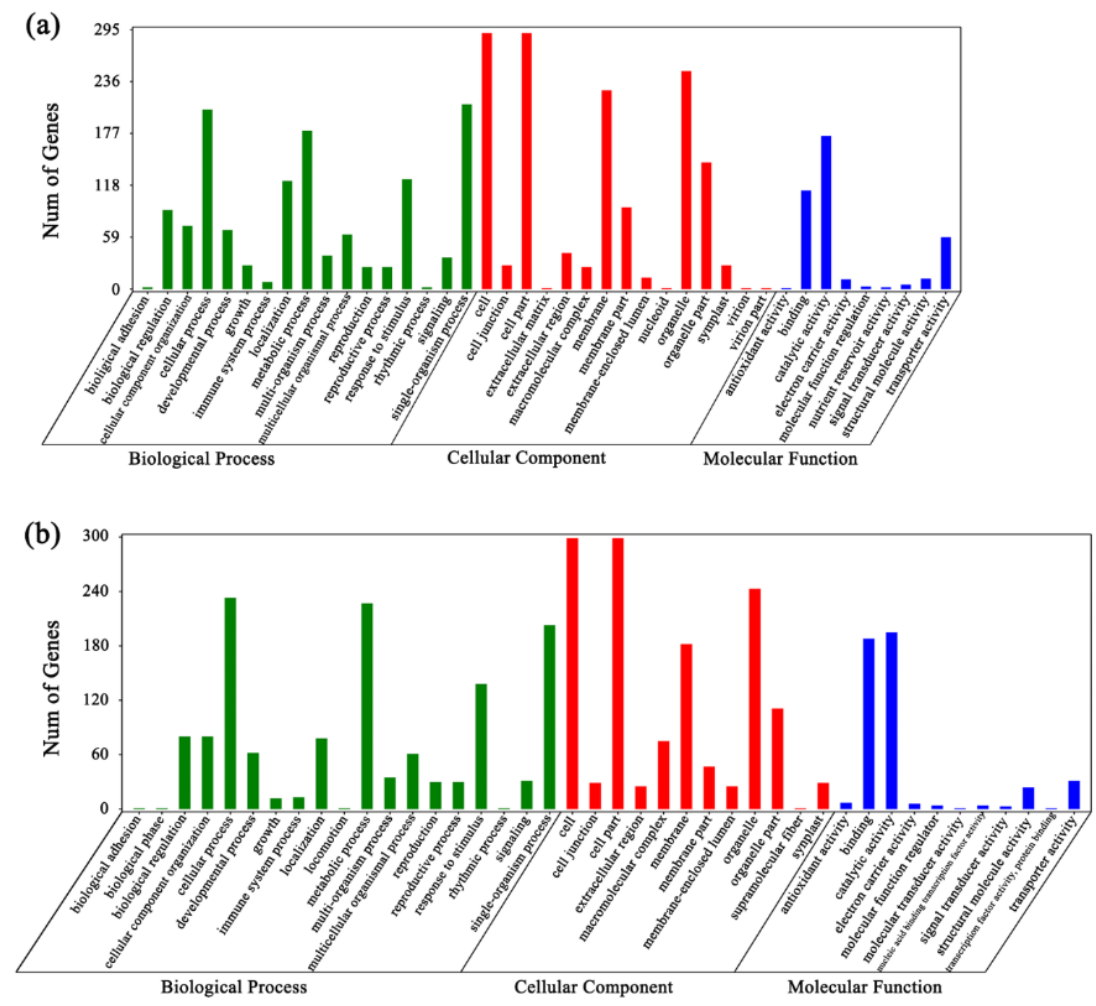

Fig. 3: GO enrichment analysis of differently expressed membrane proteins (a) up-regulated expressed membrane proteins in replanted $R$. glutinosa, (b) down-regulated expressed membrane proteins in replanted $R$. glutinosa

metabolism, membrane trafficking and environmental response (Table 1). We also identified a large number of membrane receptor proteins (such as $L R R-R L K, \mathrm{G}$-protein coupled receptors, interleukins) in the SP $R$. glutinosa. It is noteworthy that there were 18 differential membrane proteins involved in plant pathogen interaction, including $L R R-R L K$ protein kinase, calmodulin, and calcium-dependent protein kinase, which indicated that the pathogenic bacterial invasion is one of the factors inducing replanting disease of $R$. glutinosa. In addition, 44 proteins involved in endocytosis, phagosomes, and peroxisomes, indicated that metabolism and signal transduction in SP $R$. glutinosa were active. At the same time, there were 13 proteins involved in the sensing and transduction of hormonal signals (including gibberellin, auxin, and brassinolide), which implied that hormones played the important regulatory role in response to replanting stress.

In this study, we discovered 10 up-regulated $L R R$ $R L K$ s proteins closely related to the immune system in the SP $R$. glutinosa. Through the evaluation on the receptor kinase activity of these $L R R-R L K \mathrm{~s}$, we were able to assess the invasion degree of pathogenic microorganism in the replanting soil. $L R R-R L K \mathrm{~s}$ were important membrane proteases that activated the phosphorylation of intracellular 

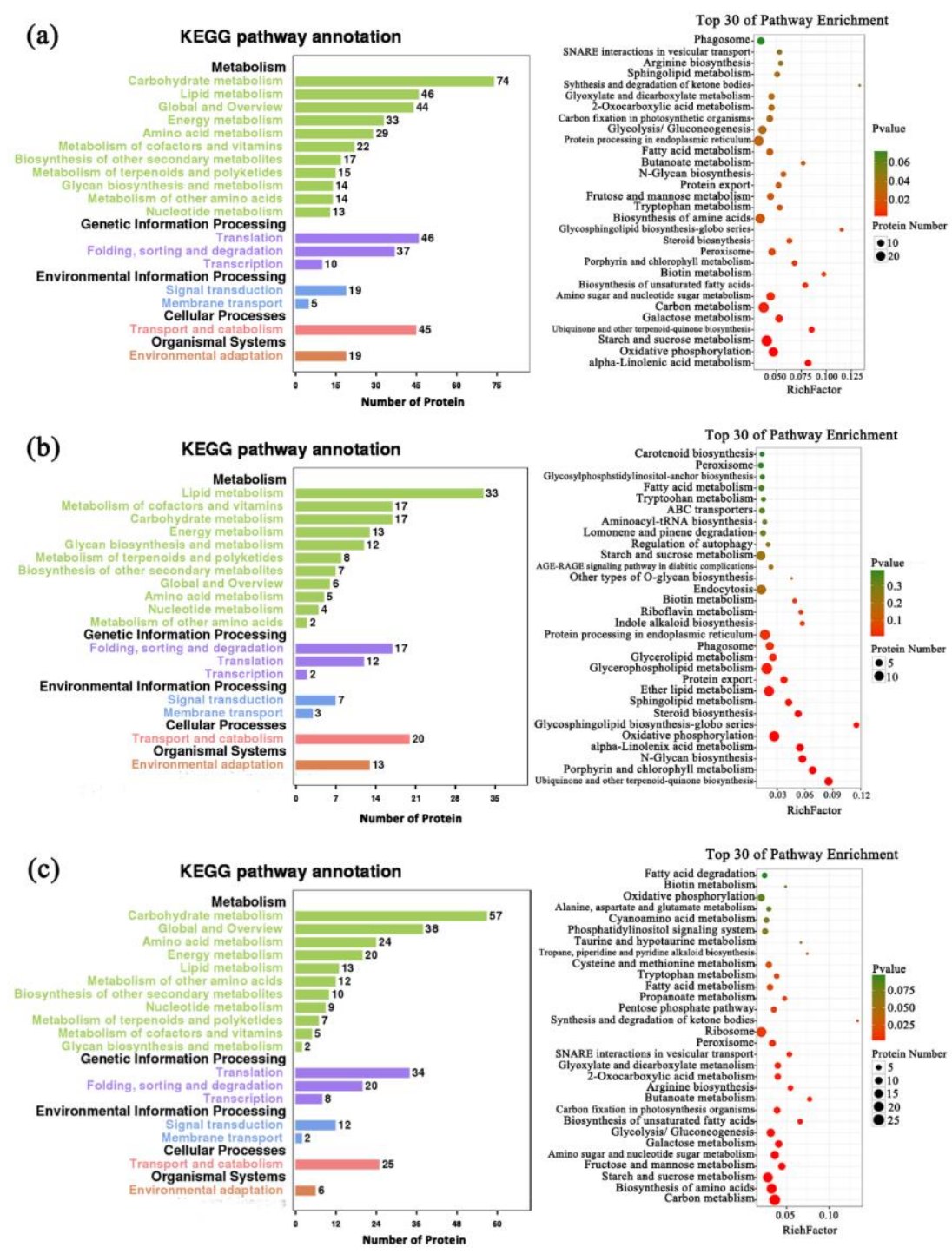

Fig. 4: Pathway enrichment analysis of differently expressed membrane proteins (a) total differently expressed membrane proteins between FP and SP $R$. glutinosa, (b) up-regulated membrane proteins in replanted $R$. glutinosa, (c) down-regulated membrane proteins in replanted $R$. glutinosa

$\mathrm{FP}=$ the $R$. glutinos $a$ first planted in the field; $\mathrm{SP}=$ the $R$. glutinosa replanted in the same field continuously

kinase domains through the specific binding of extracellular signal-receiving sites to extracellular molecules, thereby accomplished transmembrane signal transduction. $L R R-R L K \mathrm{~s}$ play an essential role in pathogen infection in plants. In order to further confirm the role of $L R R-R L K \mathrm{~s}$ in the formation of replanting stress, we infected the roots of $R$. glutinosa plants with $F$. oxysporum, an SP $R$. glutinosa rhizosphere-specific pathogenic fungi isolated by our research team in previous studies. As a result, we found that $F$. oxysporum significantly induced the up-regulated expression of $L R R$ $R L K$ s genes (Unigene7473_All, CL4884.Contig2_All and CL7625.Contig2_All). The expression of these genes was consistent with our previous studies (Fig. 5).

\section{Discussion}

Plant cell membranes play the important role in sensing external signals, dividing organelles, ion exchange, and responding to external stresses. Therefore, the membrane system was important to survive of plants and the important channel for communicating with environment (Liu et al. 2014; Sun and Wang 2009). Replanting disease mainly caused by the change of soil physical and chemical properties, allelochemical autotoxicity, and the imbalance of rhizosphere microbials (Lin et al. 2011, 2015; Wu et al. 2015; Zhang et al. 2018). The root membrane system may be plays the important role in sensing and responding to replanting stress. The study on 


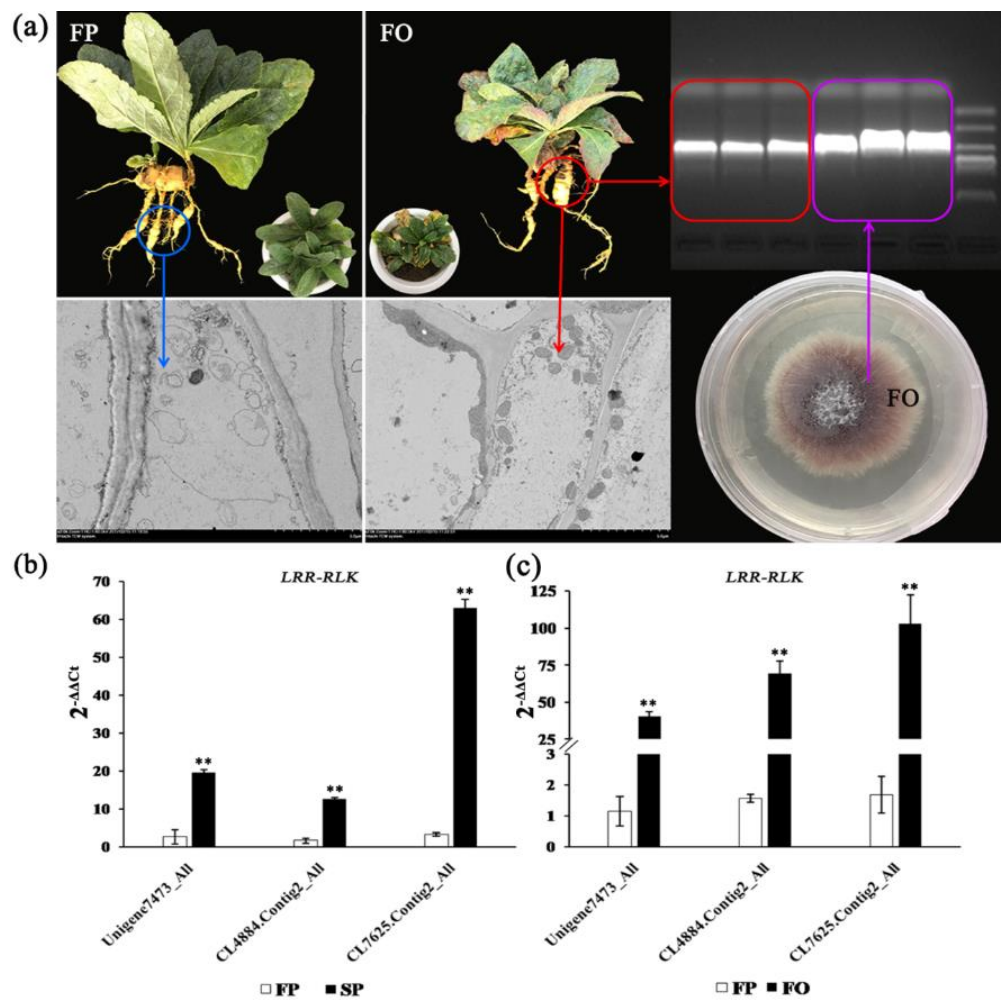

Fig. 5: $L R R-R L K$ s expression analysis in FP and SP $R$. glutinosa (a) Root electron microscopy analysis of $R$. glutinosa under $F$. oxysporum (FO) infection, (b) Key $L R R-R L K$ s expression analysis in FP and SP $R$. glutinosa, (c) Key $L R R$-RLKs expression analysis in $\mathrm{FP}$ and the $R$. glutinosa infected by $F$. oxysporum (FO)

$L R R-R L K \mathrm{~s}=$ Leucine-rich repeat receptor-like kinases; $\mathrm{FO}=R$. glutinosa infected by $F$. oxysporum

$\mathrm{FP}=$ the $R$. glutinos a first planted in the field; $\mathrm{SP}=$ the $R$. glutinos $a$ replanted in the same field continuously

the key membrane proteins in response to replanting stress is thus important for analyzing the formation mechanism of replanting disease in $R$. glutinosa.

After removing the non-membrane proteins, function analysis revealed that the differential membrane proteins which related to immune system, calcium signal response, and reactive oxygen species (ROS) metabolism were upregulated in the SP $R$. glutinosa. In this study, $10 L R R-R L K \mathrm{~s}$ proteins closely related to the immune system were upregulated in the SP R. glutinosa. LRR-RLKs are the important membrane proteins in response to pathogen infection, and usually play the important role in plant defense response, growth and development, and hormone regulation (Osakabe et al. 2013; Wu and Zhou 2013; He and Wu 2016). LRR-RLKs receptor proteins were induced under various stress conditions (such as pathogen infection, high salt, abscisic acid or injury, etc.) (Jung et al. 2004; Laura et al. 2009; Yang et al. 2012). Previous studies found that the rhizosphere microbes in SP $R$. glutinosa largely changed from bacterial to fungal, which led to proliferation of large number of pathogenic microorganisms (Chen et al. 2008; Lin et al. 2011). Numerous studies have confirmed that the microecological imbalance in rhizosphere mediated by allelochemical autotoxins promoted the formation of replanting disease (Qiu et al. 2010; Li et al. 2012a, b; Zhao et al. 2016). Fusarium oxysporum, a rhizosphere-specific pathogenic fungi of SP $R$. glutinosa isolated by our research team in previous studies (Li et al. 2016). To further confirm the role of $L R R-R L K \mathrm{~s}$ in the SP $R$. glutinosa, $R$. glutinosa plants were inoculated in vitro using $F$. oxysporum. $F$. oxysporum significantly induced the up-regulation of $L R R$ RLKs genes (Unigene7473_All, CL4884.Contig2_All and CL7625.Contig2_All), which further confirmed the relationship between the rhizosphere pathogen in SP $R$. glutinosa and the death of replanting plants.

Replanting stress induced membrane peroxidation in root tissue cells of $R$. glutinosa. The immune response triggered by pathogenic microbes rapidly induced downstream signaling transduction including calcium signaling, ROS and other signaling pathways, which further activate the expression of resistance genes (Poltronieri 2017; Zhou and Zhang 2020). In plants, active oxygen was involved in the earlier response to both biotic and abiotic stresses. Stresses could significantly induce the production of various forms of ROS, such as superoxide, hydrogen peroxide $\left(\mathrm{H}_{2} \mathrm{O}_{2}\right)$, and hydroxyl radicals (Omar et al. 2020). The massive accumulation of ROS destroyed the redox balance in plant cells and resulted in the oxidative damage to cellular biomolecules, such as lipids, proteins, and nucleic acids (Cheng et al. 2013). Plants eliminated excessive ROS mainly through antioxidant enzymes (such as superoxide 
dismutase, peroxidase, and catalase), reduced lipid peroxidation, improved cell metabolism, and ultimately alleviated the oxidative damage caused by stress. In this study, seven types of peroxisome-related proteins were identified, of which, there were three POD and two ACOX1 were significantly down-regulated in replanted $R$. glutinosa. In plants, ACOX1 catalyzes acyl-CoA combined with oxygen, and formed trans-2, 3-dehydroacyl-CoA and $\mathrm{H}_{2} \mathrm{O}_{2}$. In addition, in cellular membrane, the phospholipase $\mathrm{D}$ were found to induce $\mathrm{H}_{2} \mathrm{O}_{2}$ biosynthesis. For example, Qu et al. (2014) discovered that the up-regulated expression of the PLD gene in Vicia faba root tips and Arabidopsis thaliana could induce stomatal closure and $\mathrm{H}_{2} \mathrm{O}_{2}$ production $(\mathrm{Qu}$ et al. 2014). More importantly, Phospholipase D (PLD, EC 3.1.4.4) is a type of lipolytic enzyme that hydrolyzes lecithin, phosphatidylethanolamine, and phosphatidylglycerol under the induction of $\mathrm{Ca}^{2+}$, and $\alpha$ PLD also hydrolyzed phosphatidylinositol diphosphate under acidic or $\mathrm{Ca}^{2+}$ stimulation (Rahier et al. 2016). Previous studies have found that calcium signaling deeply involved in the formation of $R$. glutinosa replanting disease (Yang et al. 2015). Furthermore, some studies on replanting disease in other plants demonstrated that calcium signaling play the important role in response to allelochemical stress (Chi et al. 2011). Therefore, calcium signaling-related proteins might participate in the replanting disease as the downstream of receptor protein kinases. The up-regulated expression of the PLD proteins and cellulose synthase in the SP $R$. glutinosa root cells might lead to the lipid peroxidation of the cell membrane and disruption of cell membrane structure. Overview, the differential expression of the identified enzymes related to $\mathrm{H}_{2} \mathrm{O}_{2}$ synthesis was up-regulated in the SP $R$. glutinosa root cells, while catabolism decreased, which led to oxidative stress in the root cells. Excess $\mathrm{H}_{2} \mathrm{O}_{2}$ in the cell oxidized cell membrane structure and destroyed biofilm structure.

In conclusion, based on the extraction of membrane proteins and iTRAQ technology, two important molecular events that occurred in cellular membrane of replanted $R$. glutinosa including the imbalance of ROS metabolism and immune response, were identified in this study. More importantly, this cellular process has obviously proved to relate to the formation of replanting disease in previous studies (Li et al. 2017; Chen and Fluhr 2018). When replanted $R$. glutinosa faced the complex environment factors in rhizosphere, the proteins located in cellular membrane were often first activated and respond to stress stimulus. At the same time, some critical cellular process including the ubiquitin-mediated proteolytic enzymes, RNA transporters, phytopathogenic interacting proteins, and dicarboxylic acid metabolism-related proteins were significantly regulated in replanted $R$. glutinosa. Formation of replanting disease was induced by multiple stress factors that mainly consisted of allelochemicals, microbes in rhizosphere and their interactions (Zhao et al. 2015; Wu et al. 2017). Replanting stress was a complex stress, which caused severe osmotic damage and membrane peroxidation in the root cells of the replanted $R$. glutinosa. Therefore, the response process mediated by replanting stress may also be a cellular process induced by the interaction of multiple proteins. This study confirmed the key damage events induced by replanting stress through the analysis of differential membrane proteins between FP and SP $R$. glutinosa, although the specific regulatory relationships of these differential membrane proteins and their signal transduction processes will still require further experimental verification, our findings provide the data foundation for exploring the formation mechanism of replanting disease.

\section{Conclusion}

This study screened a suitable method for extracting membrane proteins from the root tissue of $R$. glutinosa. This extract method could highly effectively extract the membrane proteins from $R$. glutinosa root tissue, the content of membrane proteins reached $61.15 \%$. The extracted membrane proteins were located in the membrane structures of various organelles, and had the rich varieties. Based on this, the differentially expressed membrane proteins in the root tissues of FP and SP were identified. When SP $R$. glutinosa plants faced the complex environment factors in rhizosphere, the stability of membrane structure was damaged, root cells formed the cell signal transduction through the endocytosis by phagosomes, transmembrane transport metabolism (dicarboxylic acid metabolism), proteins export, and related metabolic regulation processes. Root tissue cells of SP induced the external environmental signals, activated corresponding metabolic processes and changed the process of protein transcription, translation and folding by regulating the expression level of membrane proteins, and eventually led to the replanting disease of $R$. glutinosa. These results provided the theoretical basis for completing signal transduction pathway of replanted $R$. glutinosa and elucidating the key mechanisms associated with replanting stress.

\section{Acknowledgements}

This study was supported by the National Natural Science Foundation of China (Grant No. 81573538, 81503193, 81603243 and 81403042) and the Key Scientific Research Project of the higher Education Institutions of Fujian Province of China (No. JK2015013).

\section{Author Contributions}

FJF, CYY and SYZ designed and performed the research, analyzed data and wrote the manuscript. FJF, MJL, SQC, LG, BZ and AGC participated to analyze data and helped in drafting the manuscript. $\mathrm{ZYZ}$ contributed to the interpretation of results and coordinated the study. All authors have read and approved the final draft. 


\section{Conflicts of Interest}

Authors declare no conflict of interest.

\section{Data Availability}

Data presented in this study will be available on a fair request to the corresponding author.

\section{Ethics Approval}

Not applicable in this paper

\section{References}

Chen H, HR Hao, J Xiong, XH Qi, CY Zhang, WX Lin (2008). Effects of successive cropping Rehmannia glutinosa on rhizosphere soil microbial flora and enzyme activities. Chin $J$ Appl Ecol 18:2755-2759

Chen JP, KX Zhang, Y Liu, XH Gai, T Ren, SX Liu, CW Tian (2021). Research progress on chemical constituents and pharmacological actions of Rehmannia glutinosa. Chin Herb Med 52:1772-1784

Chen T, R Fluhr (2018). Singlet oxygen plays an essential role in the root's response to osmotic stress. Plant Physiol 177:1717-1727

Cheng SJ, DQ Tang, QL Liu (2013). Reactive oxygen species homeostasis of two Lonicera species under salt stress. J Nanj For Univ 37:137-141

Chi WC, YA Chen, YC Hsiung, SF Fu, CH Chou, N Trinh, YC Chen, HJ Huang (2013). Autotoxicity mechanism of Oryza sativa: Transcriptome response in rice roots exposed to ferulic acid. $B M C$ Genomics 14; Article 351

Chi WC, SF Fu, TL Huang, YA Chen, CC Chen, HJ Huang (2011). Identification of transcriptome profiles and signaling pathways for the allelochemical juglone in rice roots. Plant Mol Biol 77:591-607

Du Y, XK Chen, YL Guo, XJ Zhang, HX Zhang, FF Li, GY Huang, YL Meng, WX Shan (2020). Phytophthora infestnas RXLR effector PITG20303 targets a potato MKK1 protein to suppress plant immunity. New Phytol 229:501-515

Guo GY, MJ Li, PF Wang, FQ Wang, HQ He, J Li, HY Zheng, XJ Chen, ZY Zhang (2013). Abnormal change of calcium signal system on consecutive monoculture problem of Rehmannia glutinosa. Chin $J$ Chin Mater Med 38:1471-1478

He K, Y Wu (2016). Receptor-like kinases and regulation of plant innate immunity. Enzymes 40:105-142

He XW, YH Huo, XX Liu, QQ Zhou, SQ Feng, X Shen, BH Li, SJ Wu, XS Chen (2018). Activation of disease resistance against Botryosphaeria dothidea by downregulating the expression of MdSYP121 in apple. Hortic Res 5:24-40

Huang LF, LX Song, XJ Xia, WH Mao, K Shi, YH Zhou, JQ Yu (2013). Plant-soil feedbacks and soil sickness: From mechanisms to application in agriculture. $J$ Chem Ecol 39:232-242

Huang RZ, XC Huang, B Zhang, HY Jia, ZX Liao, HS Wang (2018). 16-Ocaffeoyl-16-hydroxylhexadecanoic acid, a medicinal plant-derived phenylpropanoid, induces apoptosis in human hepatocarcinoma cells through ROS-dependent endoplasmic reticulum stress. Phytomedicine 41:33-44

Janicka-Russak M, K Kabała (2015). The role of plasma membrane $\mathrm{H}^{+}$ ATPase in salinity stress of plants. Prog Bot 76:77-92

Jung EH, HW Jung, SC Lee, WH Sang, S Heu, BK Hwang (2004). Identification of a novel pathogen-induced gene encoding a leucinerich repeat $(L R R)$ protein expressed in phloem cells of Capsicum annuum. Biochim Biophys Acta 1676:211-222

Laura DL, M Francisco, L Philippe, T Richard, C Jonathan, S Carolina, C Martín (2009). A novel plant leucine-rich repeat receptor kinase regulates the response of Medicago truncatula roots to salt stress. Plant Cell 21:668-680
Li HW, XL Meng (2015). Research progress on chemical constituents and pharmacological activities of Rehmannia glutinosa. Drug Eval Res 38:218-228

Li MJ, YH Yang, FJ Feng, B Zhang, SQ Chen, CY Yang, L Gu, FQ Wang, JY Zhang, AG Chen, WX Lin, XJ Chen, ZY Zhang (2017) Differential proteomic analysis of replanted Rehmannia glutinosa roots by iTRAQ reveals molecular mechanisms for formation of replant disease. BMC Plant Biol 17; Article 116

Li ZF, CL He, Y Wang, MJ Li, YJ Dai, T Wang, WX Lin (2016). Enhancement of trichothecene mycotoxins of Fusarium oxysporum by ferulic acid aggravates oxidative damage in Rehmannia glutinosa Libosch. Sci Rep 6; Article 33962

Li ZF, YQ Yang, DF Xie, LF Zhu, ZG Zhang, MJ Huang, ZQ Liu, ZY Zhang, WX Lin (2012a). Effects of continuous cropping on the quality of Rehmannia glutinosa L. and soil micro-ecology. Chin $J$ Eco-Agric 20:217-224

Li ZF, YQ Yang, DF Xie, LF Zhu, ZG Zhang, WX Lin (2012b). Identification of Autotoxic Compounds in Fibrous Roots of Rehmannia (Rehmannia glutinosa Libosch.).PLoS One 7; Article e28806

Lin S, lq dai, t chen, zf li, zy zhang, wx lin (2015). Screening and identification of harmful and beneficial microorganisms associated with replanting disease in rhizosphere soil of Pseudostellariae heterophylla. Intl J Agric Biol 17:458-466

Lin WX, CX Fang, LK Wu, GL Li, ZY Zhang (2011). Proteomic approach for molecular physiological mechanism on consecutive monoculture problems of Rehmannia glutinosa. J Integr Omics 1:287-296

Liu JJ, Z Wei, JH Li (2014). Effects of copper on leaf membrane structure and root activity of maize seedling. Bot Stud 55:47-52

Livak KJ, TD Schmittgen (2001). Analysis of relative gene expression data using real-time quantitative PCR and the $2^{-\Delta \Delta^{\mathrm{Ct}}}$ method. Methods 25:402-408

Mansour MMF (2012). Plasma membrane permeability as an indicator of salt tolerance in plants. Biol Plantarum 57:1-10

Omar NA, YA Khalid, OA Muhamad, MK Khaled, AA Sameeh, MA Jehad, MK Hazem (2020). Effect of various abiotic stressors on some biochemical indices of Lepidium sativum plants. Sci Rep 10; Article 21131

Osakabe Y, K Yamaguchi-shinozaki, K Shinozaki, LSP Tran (2013). Sensing the environment: Key roles of membrane-localized kinases in plant perception and response to abiotic stress. J Exp Bot 64:445-458

Pan Y, JN Li, SX Chen, HY Li (2013). Extraction and determination of membrane proteins in sugar beet monosomic addition line M14 under salt stress. J Eng Heilongj Univ 4:45-49

Pang QY, SX Chen, SJ Dai, YZ Chen, Y Wang, XF Yan (2010). Comparative proteomics of salt tolerance in Arabidopsis thaliana and Thellungiella halophila. J Proteome Res 9:2584-2599

Poltronieri P (2017). Plant immunity and pathogen interfering mechanisms: Effectors and bodyguards. Intl J Plant Res 7:21-28

Qiu LY, YC Qi, MD Wang, XC Jia (2010). Relationship between secondary metabolite autotoxic to plant and continuous cropping obstacles. Soils 42:1-7

Qu YN, ZF An, BC Zhuang, J Wen, Q Zhang, WH Zhang (2014). Copper amine oxidase and phospholipase D act independently in abscisic acid (ABA)-induced stomatal closure in Vicia faba and Arabidopsis. J Plant Res 127:533-544

Rahier R, A Noiriel, A Abousalham (2016). Functional characterization of the N-Terminal C2 domain from Arabidopsis thaliana phospholipase $\mathrm{D} \alpha$ and $\mathrm{D} \beta$. Biol Med Res Intl 2016:1-15

Santoni V (2007). Plant plasma membrane protein extraction and solubilization for proteomic analysis. Meth Mol Biol 355:93-109

Su BD, X Zhang, L Li, S Abbas, M Yu, YN Cui, F Baluska, I Hwang, XY Shan, JX Lin (2021). Dynamic spatial reorganization of BSK1 complexes in the plasma membrane underpins signal-specific activation for growth and immunity. Mol Plant 14:588-603

Sun YJ, GH Wang (2009). Research progress on physiology of plant cold hardiness. Crop Res 23:293-297

Wang MD, MX Chu, HL Cao, SH Hao, S Qiu, YH Zhang (2021). Discovery and identification of autotoxic substances and transformed strain of Rehmannia Glutinosa continuous cropping obstacle. J Xiny Norm Univ (Nat Sci Edit) 34:208-215 
Wang ZJ, GD Wei, ST Ma (2015). Chemical and pharmacological effects of Rehmanniae Radix polysaccharides. Chin J Exp Trad Med Form 21:231-235

Wisniewski JR, A Zougman, N Nagaraj, M Mann (2009). Universal sample preparation method for proteome analysis. Nat Meth 6:359-362

Wu H, J Xu, J Wang, X Qin, L Wu, Z Li, S Lin, W Lin, Q Zhu, MU Khan, W Lin (2017). Insights into the mechanism of proliferation on the special microbes mediated by phenolic acids in the Radix pseudostellariae rhizosphere under continuous monoculture regimes. Front Plant Sci 8; Article 659

Wu LK, WM Huang, JY Wang, HM Wu, J Chen, XJ Qin, ZY Zhang, WX Lin (2015). Diversity analysis of rhizosphere microflora of wild $R$. glutinosa grown in monocropping for different years. Acta Agron Sin 41:308-317

Wu Y, JM Zhou (2013). Receptor-like kinases in plant innate immunity. J Integr Plant Biol 55:1271-1286

Yang X, FY Deng, KM Ramonell (2012). Receptor-like kinases and receptor-like proteins: Keys to pathogen recognition and defense signaling in plant innate immunity. Front Biol 7:155-166

Yang YH, MJ Li, XY Li, XJ Chen, WX Lin, ZY Zhang (2015). Transcriptome-wide identification of the genes responding to replanting disease in Rehmannia glutinosa L. roots. Mol Biol Rep 42:881-892

Yang YH, MJ Li, XJ Chen, PF Wang, FQ Wang, WX Lin, YJ Yi, ZW Zhang, YZ Zhang (2014). De novo characterization of the Rehmannia glutinosa leaf transcriptome and analysis of gene expression associated with replanting disease. Mol Breed 34:905-915

Yuan MH, ZY Jiang, GZ Bi, K Nomura, MH Liu, YP Wang, BY Cai, JM Zhou, SY He, XF Xin (2021). Pattern-recognition receptors are required for NLR-mediated plant immunity. Nature 592:105-109
Zhang B, FL Dai, H Yin, Y Zeng, Q He, JJ Qian, XF Ou (2020). Effect of catalpol from the root of Rehmannia glutinosa on the expression of inflammatory proteins in synovium of the knee joint in rats with early osteoarthritis. Chin J Tiss Eng Res 24:4656-4661

Zhang XY, HQ Zhang, X Lou, M Tang (2019). Mycorrhizal and nonmycorrhizal Medicago truncatula roots exhibit differentially regulated NADPH oxidase and antioxidant response under $\mathrm{Pb}$ stress Environ Exp Bot 164:10-19

Zhang YQ, Y Chen, FY Lei, SJ Li, F Shi, MM Dou, LH Ma, XF Chen (2018). Advances in research on allelopathic autotoxicity effects of medicinal plants. Chin Trad Herb Drugs 49:1946-1956

Zhang ZY, H Chen, YH Yang, T Chen, RY Lin, XJ Chen, WX Lin (2010). Effects of continuous cropping on bacterial community diversity in rhizosphere soil of Rehmannia glutinosa. Chin J Appl Ecol 21:2843-2848

Zhao YP, S Lin, LX Chu, JT Gao, DS Azeem, WX Lin (2016). Insight into structure dynamics of soil microbiota mediated by the richness of replanted Pseudostellaria heterophylla. Sci Rep 6; Article 26175

Zhao YP, LK Wu, LX Chu, YQ Yang, ZF Li, S Azeem, ZX Zhang, CX Fang, WX Lin (2015). Interaction of Pseudostellaria heterophylla with Fusarium oxysporum f. spp. heterophylla mediated by its root exudates in a consecutive monoculture system. Sci Rep 5; Article 8197

Zhou JM, YL Zhang (2020). Plant immunity: Danger perception and signaling. Cell 181:978-989

Zhu GJ, MD Wang, ZW Wu, FL Sun, XC Jia (2007). Analysis of potential allelochemicals in soils around rhizosphere of Rehmannia Glutinosa Libosch by GC-MS. Henan Sci 25:255-257

Zhuang K, DL Shi, ZB Hu, FL Xu, YH Chen, ZG Shen (2019). Subcellular accumulation and source of $\mathrm{O}_{2}^{-}$and $\mathrm{H}_{2} \mathrm{O}_{2}$ in submerged plant Hydrilla verticillata (Lf) Royle under $\mathrm{NH}_{4}{ }^{+}-\mathrm{N}$ stress condition. Aquat Toxicol 207:1-12 